\title{
Correlates of Soy Food Consumption in Women at Increased Risk for Breast Cancer
}

\author{
CAROLYN Y. FANG, PhD; MARILYN TSENG, PhD; MARY B. DALY, MD, PhD
}

\begin{abstract}
Objectives The objectives of the present study were to examine sociodemographic correlates of soy food consumption among women at increased risk of breast cancer, describe factors influencing soy food consumption or nonconsumption, and identify women's sources of information about soy foods.
\end{abstract}

Design A cross-sectional, self-report survey was used to assess frequency of and factors influencing soy food consumption. Soy food intake was reported for the past year. Subjects/setting Participants were 452 women with family histories of breast cancer who were enrolled in a cancer risk assessment program.

Statistical analyses performed Comparisons between consumers and nonconsumers of soy foods were performed using multivariate logistic regression and $\chi^{2}$ analyses.

Results Thirty-two percent reported soy food consumption. Commonly consumed soy foods were vegetable burgers, tofu, and soymilk. Consumers of soy foods were more likely to have higher levels of education and report eating five or more daily servings of fruits and vegetables. The primary reason for consumption of soy foods was eating a healthful diet, whereas insufficient knowledge about soy food preparation was the primary reason stated for nonconsumption. Both consumers and nonconsumers reported obtaining information about soy foods from magazines, friends, and newspapers. Consumers also indicated using the Internet to seek information.

Conclusions These findings contribute to our understanding of the level of soy intake among women at increased risk for breast cancer and highlight potential factors that may influence women's decisions regarding soy food consumption. Women, particularly in this vulnerable population, would benefit from clear messages regarding the health effects of soy.

C. Y. Fang is an associate member, M. Tseng is an associate member, and M. B. Daly is a senior member, Division of Population Science, Fox Chase Cancer Center, Cheltenham, PA. he promise of health benefits from soy has contributed to the recent increase in the availability of soy-containing foods $(1,2)$. Since 1995, sales of soy-based products have increased 20\% per year, with a large boost in 1999 when the US Food and Drug Administration approved a health claim for soy's cardiovascular benefits (3). Largescale dietary trends toward vegetarianism and ready-to-eat meals are also driving an increase in the consumption of soy-based meat alternatives $(4,5)$. As a result, soy foods are moving rapidly from a niche market to mainstream acceptance.

Given recent studies reporting an inverse relationship between soy intake and breast cancer risk (6-8), awareness and use of soy foods may be particularly high among women at increased risk for breast cancer. Likewise, beliefs about the benefits of soy in reducing menopausal symptoms may motivate women at risk for breast cancer who are perimenopausal or postmenopausal to try alternatives to estrogen to treat menopausal symptoms (9). However, despite the widespread promotion of soy and evidence of its health benefits with respect to heart disease risk, its effects on breast health, especially in non-Asian women, are unknown. Indeed, studies of soy effects on breast density and fluid suggest the possibility that high levels of intake might actually increase breast cancer risk in US women (1012) — of particular concern among women already at increased risk for the disease.

Information about correlates of and factors motivating soy food consumption among women at risk for breast cancer is limited. Therefore, the objectives of the present study were to: (a) examine sociodemographic and lifestyle correlates of soy food consumption among women at increased risk for breast cancer, (b) describe primary reasons for consumption or nonconsumption of soy foods, and (c) identify sources from which at-risk women obtain information about soy food. These findings will contribute to our understanding of potential factors influencing soy food consumption in an at-risk population.

\section{METHODS \\ Participants}

Questionnaires were sent to 893 women enrolled in a family risk assessment program, an education/counseling program for first- and second-degree relatives of cancer patients. Three women had died, and seven women were ineligible due to having participated in a related study, leaving 883 potential respondents. Of these 883 women, 17 indicated that they were not interested in participating, 44 could not be contacted, and 370 did not return packets, leaving a sample of 452 respondents ( $54 \%$ response rate). 


\begin{tabular}{|c|c|c|c|c|}
\hline Food item (serving size) & \multicolumn{2}{|c|}{$\begin{array}{l}\text { Consumers Who } \\
\text { Consumed Item }\end{array}$} & $\begin{array}{l}\text { No. servings } \\
\text { per month } \\
\left(\text { mean } \pm S D^{a}\right)\end{array}$ & Range \\
\hline Vegetable burger (1 patty) & 84 & 57.9 & $2.45 \pm 3.66$ & $0-22$ \\
\hline Tofu (3 to $4 \mathrm{oz}$ ) & 63 & 43.4 & $2.43 \pm 5.11$ & $0-33$ \\
\hline Green soybeans (1/2 cup) & 36 & 24.8 & $1.12 \pm 2.65$ & $0-12$ \\
\hline Miso soup ( 1 cup) & 29 & 20.0 & $0.94 \pm 3.23$ & $0-30$ \\
\hline Soy or tofu-based cheese (1 oz) & 27 & 18.6 & $1.71 \pm 7.68$ & $0-75$ \\
\hline Meatless chicken (1 patty) & 18 & 12.4 & $0.51 \pm 1.88$ & $0-12$ \\
\hline Soy protein-based bars (1) & 17 & 11.7 & $0.44 \pm 1.08$ & $0-6$ \\
\hline Soy protein-based powders (1 scoop) & 17 & 11.7 & $0.37 \pm 1.05$ & $0-5$ \\
\hline Soy cereal & 12 & 8.3 & $0.25 \pm 0.84$ & $0-4$ \\
\hline Soy bacon (2 slices) & 11 & 7.6 & $0.32 \pm 1.54$ & $0-12$ \\
\hline Soy or tofu-based yogurt (1 cup) & 9 & 6.2 & $0.51 \pm 3.00$ & $0-30$ \\
\hline Other soy meat (eg, soy meatballs, Tofurkey ${ }^{\mathrm{b}}$ ) & 7 & 4.8 & $0.06 \pm 0.29$ & $0-2$ \\
\hline Yuba (soymilk skin or film) (3 to $4 \mathrm{oz}$ ) & 6 & 4.1 & $0.26 \pm 1.53$ & $0-12$ \\
\hline Soy sausage & 5 & 3.4 & $0.09 \pm 0.55$ & $0-5$ \\
\hline Textured vegetable protein (TVPC) & 5 & 3.4 & $0.06 \pm 0.36$ & $0-3$ \\
\hline Miso (1 Tbs) & 5 & 3.4 & $0.08 \pm 0.39$ & $0-2$ \\
\hline Soybean sprouts (1/2 cup) & 4 & 2.8 & $0.06 \pm 0.30$ & $0-2.5$ \\
\hline Soybeans (1/2 cup) & 4 & 2.8 & $0.07 \pm 0.22$ & $0-1$ \\
\hline Soy chips & 4 & 2.8 & $0.10 \pm 0.61$ & $0-5$ \\
\hline Soy flour & 4 & 2.8 & $0.03 \pm 0.22$ & $0-2$ \\
\hline
\end{tabular}

\section{Procedures}

A self-report questionnaire was used to elicit information about frequency of consumption of soy and other isoflavonecontaining foods, reasons for consumption or nonconsumption, and sources of information about soy foods. All respondents completed the soy food frequency questionnaire. Selfcategorized consumers of soy foods were instructed to complete items assessing various reasons for eating soy, whereas self-categorized nonconsumers completed items concerning reasons for not eating soy. Finally, all respondents completed the section that assessed sources of information about soy foods. This study was approved by the Institutional Review Board of Fox Chase Cancer Center.

\section{Measures}

Soy Food Intake. For the assessment of soy food and isoflavone intake, participants completed a 26 -item food frequency questionnaire that included traditional soy foods (eg, tofu), soy protein-based products (eg, protein bars), and some non-soy but isoflavone-containing foods (eg, asparagus). For each food item, participants indicated the average frequency that they consumed a specified portion size of the food during the previous year, with options ranging from "never, or less than once per month" to "6+ per day." The list of soy food items was developed from tables and databases representing all current information about the isoflavone content of more than 100 food items (13-18) and was supplemented with information from soy food manufacturers and with detailed soy intake information from a pilot study of family risk assessment program participants. The questionnaire also included an open-ended section so respondents could report intake of other soy-based foods eaten at least once per month (see the Table for a list of soy food items considered in our analysis). Non-soy but isoflavone-containing foods such as asparagus or pinto beans were not considered. For soy protein bars and protein powders, we estimated the mean frequency of intake using women's responses to two items: (a) the frequency of consumption of any protein bars or powders, and (b) how often the protein bars or powders that were consumed were soy protein-based. Thus, women's reports that the protein bars/powders they consumed were "never or almost never," "sometimes," "often," or "always or almost always" soy proteinbased were multiplied, respectively, by $0,0.33,0.67$, or 1.0 times the frequency of all protein bar/powder consumption in order to calculate the frequency of soy pro- 
tein bar/powder intake. When women reported that they did not know if a bar/powder contained soy, we assumed the product did not have soy.

Reasons for Consumption or Nonconsumption of Soy. Respondents were identified as soy consumers if they indicated as such when asked, "If you do eat soy foods, check here." Consumers were instructed to complete 10 items describing various reasons for consuming soy. Respondents were identified as nonconsumers if they checked the item, "If you do not eat soy foods, check here." Nonconsumers were asked to complete six items describing various reasons for not eating soy. Possible responses for all items ranged from 1 =strongly disagree to 5 =strongly agree.

Sources of Information. Respondents were asked whether they look for information about soy or soy food products. In addition, from a list of possible sources, respondents checked all sources from which they obtain information about soy and/or soy foods.

Demographic Variables and Health Behaviors. After enrollment in the Family Risk Assessment Program, participants completed a questionnaire assessing demographic background, family history of cancer, health behavior (eg, smoking status, physical activity), and diet. Based on a pedigree review, women were classified as having risk of breast cancer that was either sporadic (ie, single occurrence of cancer), familial (ie, a pattern of cancers that does not fit a known cancer family syndrome), or hereditary (ie, a hereditary [vertical] pattern of inheritance of cancers fitting a known cancer family syndrome) (19).

With respect to health behaviors, women were categorized as either current smokers or nonsmokers. A dichotomous activity variable was also created such that women engaging in 2.5 or more hours of moderate to strenuous physical activity per week were categorized as having high activity, and those engaging in fewer than 2.5 hours were scored as having low activity.

Diet during the previous year was assessed using the Harvard Diet Assessment Form (20). The Harvard Diet Assessment Form requested information about 126 food items and was used to obtain estimates of percentage of total energy from fat. Participants were categorized as having high fruit and vegetable intake if they reported consuming five or more servings of fruits and vegetables per day based on their responses on the Harvard Diet Assessment Form.

\section{Statistical Analyses}

For each soy food, frequency of intake was converted to servings per month. We summed across all food items to determine total number of servings of soy foods per participant per month. The percentage of participants who consumed each food as well as the mean ( \pm standard deviation [SD]) servings per month among consumers was calculated. Logistic regression analyses were used to examine sociodemographic and lifestyle correlates of soy food consumption. $\chi^{2}$ analyses were used to investigate potential differences in sources of soy food information between soy consumers and nonconsumers. Analyses were considered statistically significant at $P<.05$ and were conducted using SPSS Version 11.0 (SPSS, Inc, Chicago, IL, 2001).

\section{RESULTS}

The present sample was comprised of 452 women (mean age $\pm \mathrm{SD}=41.88 \pm 5.35$ years). The sample was predominantly non-Hispanic white (96\%), $1 \%$ black/African American, 1\% Asian, 1\% multiple racial/ethnic background, and $1 \%$ unknown/unreported. The majority (77\%) reported being currently married/living as married. Approximately $12 \%$ had a high school education or less, $20 \%$ had attended some college or vocational/technical school, $40 \%$ of respondents had a college degree, and $26 \%$ had a postgraduate degree.

To determine whether study respondents differed from nonrespondents on available data, we compared the two groups using one-way analysis of variance for continuous variables and $\chi^{2}$ tests for categorical variables. Respondents tended to be slightly older $(41.89 \pm 5.34$ years, mean \pm SD) compared with nonrespondents $(40.70 \pm 5.44$ years), $\mathrm{F}=10.82, P<.001$. A greater percentage of respondents $(66.4 \%)$ were college-educated compared with nonrespondents $(56.6 \%), \chi^{2}(1)=9.01, P<.01$. There were no differences between respondents and nonrespondents in marital status, family history of breast cancer, or health behaviors (ie, daily intake of fruits and vegetables, exercise levels, and smoking status).

\section{Prevalence of Soy Food Consumption}

Overall, $43 \%(n=193)$ of participants reported eating at least one soy food per month, regardless of how they classified themselves with respect to soy food consumption. The majority (123 of 193, 64\%) consumed soy foods more than twice a month. Mean frequency of soy food consumption in the overall sample was 6.32 servings per month $(\mathrm{SD}=15.45$, median $=2.00$, range $=0$ to 131$)$.

One hundred eighteen women categorized themselves as consumers, and 283 women categorized themselves as nonconsumers. The remaining 51 women who described themselves as both $(n=15)$ or neither $(n=36)$ were categorized as consumers or nonconsumers based on their soy food consumption. Specifically, 27 of the 51 respondents reported intake of at least one soy food item and therefore were classified as consumers. Thus, a total of 145 respondents $(32 \%)$ were classified as consumers, and the remaining 307 respondents were classified as nonconsumers. Mean frequency of soy food intake among consumers was 18.35 servings per month $(\mathrm{SD}=24.14$, median $=10.00$, range $=0$ to 131). The soy food items eaten by the highest percentages of consumers were vegetable burgers, tofu, soymilk, soynuts, and green soybeans (Table). The most frequently consumed soy foods on average were soymilk, soynuts, vegetable burgers, and tofu (Table).

\section{Correlates of Soy Food Consumption}

Using logistic regression analyses, we examined whether age, ethnicity, educational level, marital status, and fruit and vegetable intake were associated with soy food consumption. The results indicated that compared to nonconsumers, consumers were more likely to have received a college education or beyond (odds ratio $=1.78,95 \%$ confidence interval $=1.13$ to $2.82, P<.01$ ) and to obtain five or more daily servings of fruits and vegetables (odds ratio $=2.55$, 95\% confidence interval $=1.67$ to $3.89, P<.001$ ). 


\section{Reasons for soy food consumption: "I eat soy foods because..."}

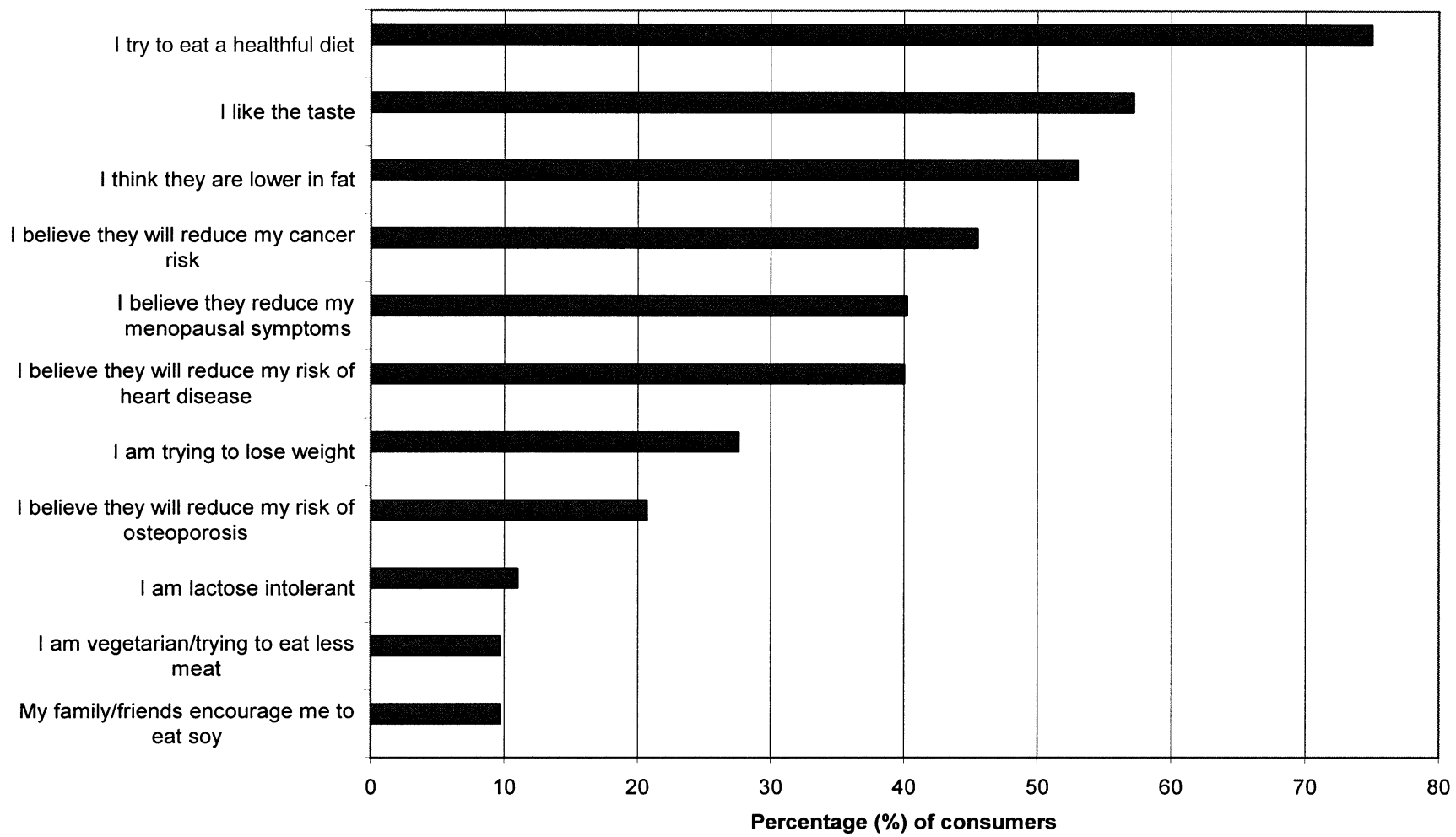

Figure 1. Percentage of consumers (women at increased risk of breast cancer) who endorsed each statement as a reason for eating soy foods.

Because data were incomplete for smoking status $(n=434)$, physical activity $(n=211)$, fat intake $(n=430)$, and classification of risk based upon family history of breast cancer $(n=246)$, separate logistic regression analyses were conducted with each of these variables separately, while controlling for the five sociodemographic and diet variables listed earlier. In general, consumers of soy foods were slightly more likely to report high levels of physical activity and less fat in their diets compared with nonconsumers, although these associations did not reach statistical significance (both $P$ values $=.09$ ). No associations were observed between soy consumption and smoking status or level of breast cancer risk.

\section{Reasons for Consumption and Nonconsumption}

The percentage of respondents who reported that they agree or strongly agree with each given statement regarding soy consumption or nonconsumption is presented in Figures 1 and 2, respectively. Among consumers, the primary reason for consumption was trying to eat a healthful diet (see Figure 1). In addition, the majority of soy food consumers agreed that they like the taste of soy foods and that they believe soy food alternatives are lower in fat. Almost half (45\%) reported a reduction in cancer risk as a reason for their soy consumption. Among 82 menopausal women, $40 \%$ reported that they consume soy foods to reduce menopausal symptoms.

Among nonconsumers, the primary reason for noncon- sumption was not knowing how to prepare or cook soy foods (see Figure 2). More than one third reported they dislike the taste of soy foods. Interestingly, 22 nonconsumers $(7 \%)$ wrote that they avoided soy foods because of a potential association between the phytoestrogens in soy foods and breast cancer. In fact, some respondents indicated that they had been instructed by a health professional to not eat soy foods.

\section{Sources of Information about Soy Foods}

A greater percentage of consumers (62.9\%) reported seeking information about soy and soy food products compared with nonconsumers $(15.8 \%), \chi^{2}(1)=99.92, P<.001$. Both consumers and nonconsumers reported obtaining information from magazines, newspapers, friends, and health newsletters. However, a greater percentage of consumers were likely to obtain information from magazines $(69.7 \%)$, health newsletters $(51.7 \%)$, and friends $(35.9 \%)$ compared with nonconsumers $(54.4 \%, 30.9 \%$, and $24.1 \%$ for magazines, newsletters, and friends, respectively), all $P<.05$. Further, more consumers reported using the Internet $(26.2 \%)$ and books $(25.5 \%)$ as informational sources than did nonconsumers $(9.8 \%$ and $9.8 \%$, respectively), all $P<.001$. Through write-in responses, respondents reported getting soy food information from store displays, advertising on product packaging, cookbooks, restaurant menus, health spas, and scientific journals. 
Reasons for Nonconsumption: "I don't eat soy foods because..."

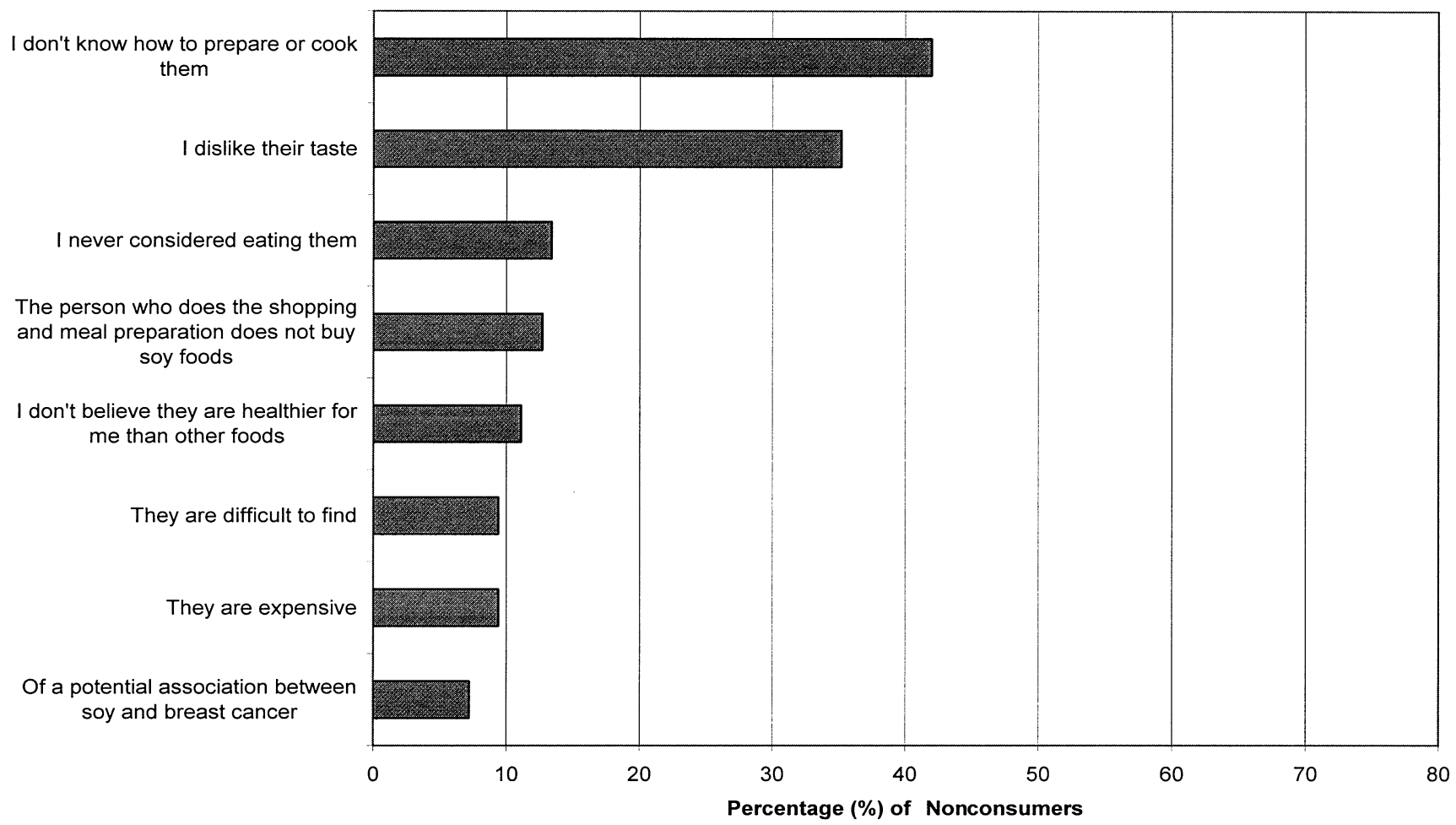

Figure 2. Percentage of nonconsumers (women at increased risk of breast cancer) who endorsed each statement as a reason for not eating soy foods.

\section{DISCUSSION}

This is one of the first studies to evaluate soy food intake among women at increased risk for breast cancer. Interestingly, although $32 \%$ of respondents self-reported being consumers of soy food, $43 \%$ recounted consuming some soy food at least once per month. Thus, a significant proportion of respondents were getting soy in their diets, even without making concerted efforts to consume soy. It is also notable that compared with other studies in which consumers incorporated soy foods into their diets only once or twice per month (21), the majority of consumers $(64 \%)$ in the present sample reported consumption in a frequency more than twice per month. The higher prevalence and frequency of soy consumption in the present sample suggests that at-risk women may be more inclined to incorporate soy foods into their diets, perhaps in an effort to establish healthful dietary behaviors.

Women reported eating a variety of soy foods, including not only traditional foods such as soymilk, tofu, and green soybeans as reported in other studies (22), but also modern soy-based items such as vegetable burgers and protein bars. Almost $30 \%$ of consumers in the present sample also reported eating soy nuts, a food item not included in previous soy food questionnaires. Women cited several reasons for consuming soy foods, with the majority of consumers being motivated to eat a more healthful diet. In addition, nearly half of the consumers cited cancer risk reduction as motivating their soy food consumption. Notably, a greater proportion of women reported consuming soy to reduce cancer risk than to reduce their risk of heart disease, even though the only health claim for soy permitted by the Food and Drug Administration is related to heart disease (3). Further, exploratory post hoc analyses revealed that women who believed soy had cancer-protective properties were less likely to report obtaining information about soy from health professionals than nonconsumers reporting a possible soy-breast cancer association as a reason for nonconsumption. Given that high levels of soy intake might increase breast cancer risk (10-12), our findings highlight the need for clear, consistent messages regarding the potential health benefits or risks of consuming soy foods, particularly in the context of cancer risk.

The primary reasons for nonconsumption were not knowing how to prepare soy foods and a dislike for the taste of soy products. Negative perceptions of soy-related foods, particularly with respect to their taste and/or texture, are not uncommon (23). Given that taste has been found to be the most influential factor determining Americans' food choices (24), negative perceptions regarding the sensory quality of soy foods seem to be a significant factor for nonconsumers.

Most respondents reported obtaining information about soy and soy foods from magazines, health newsletters, friends, and newspapers, whereas few reported obtaining information from health professionals. Our findings are consistent with studies that have found that cancer patients and their relatives generally seek infor- 
mation from acquaintances, television $(25,26)$, newspapers, and magazines (27), and that patients actively seek information (ie, seeking health information from medical books, telephone helplines, or the Internet) only to a limited degree (27). Of concern is the fact that media reports, particularly those presented in popular magazines or as brief news items, rarely provide enough information for readers to fully understand the issues presented (28). Thus, health professionals should take an active role in communicating and clarifying such information to patients, consumers, and public information/ media channels.

\section{Limitations}

One limitation of the present study was the response rate. Although our response rate may seem less than optimal, it compares favorably with other published studies of soy intake $(8,18)$ and dietary behavior and cancer (29). However, we acknowledge that a 54\% response rate poses the possibility of bias. Given that respondents tended to be more well-educated than nonrespondents, and that educational level was associated with soy food consumption, it is possible that nonconsumers were underrepresented in our sample. However, we did not observe any differences in other health behaviors or level of cancer risk, which would have increased our concerns about bias. Thus, there is no reason to believe that the information elicited (eg, types of soy foods, reasons for consumption and nonconsumption, and sources of information) would differ between those who responded and those who did not.

\section{Most respondents reported obtaining information about soy and soy foods from magazines, health newsletters, friends, and newspapers, whereas few reported obtaining information from health professionals.}

Another limitation involves the composition of study participants. Respondents were predominantly non-Hispanic white, fairly well-educated, and enrolled in a riskassessment program. Therefore, they are more likely to be aware of and educated about breast cancer risk factors. Although the program does not provide any education regarding the health value or nonvalue of soy foods, nor does it encourage the use of soy foods, it is possible that respondents may be more knowledgeable about and more likely to incorporate soy foods into their diet than highrisk women who are not enrolled in a cancer risk program. Thus, the present findings may not be applicable to the larger population of women at increased risk for breast cancer. Although there is a need to replicate these findings in more demographically diverse samples, our study is an important first step toward developing a greater understanding of soy intake among women at increased risk for breast cancer.
Our results suggest that soy food consumption is one behavior in a pattern of behaviors that comprise healthful lifestyle choices, such as eating five or more daily servings of fruits and vegetables. Future studies should therefore evaluate whether it is soy intake itself (regardless of the form in which it is consumed) or a particular dietary pattern (such as consuming more fruits and vegetables, less fat, and less meat) that is responsible for observed health effects.

In addition, based on our finding that a subset of women may be consuming soy for misguided reasons or nonproven health benefits, it is important for health professionals to deliver clear messages about the health benefits, if any, of soy. This can be challenging, however, because there are currently no definitive data on which to base recommendations about incorporating soy into women's diets. Research suggests that the effects of soy intake on breast cancer risk are quite complex. Soy foods may have cancer-preventive effects when they are consumed early in life (eg, during breast development), but data from other studies indicate that soy can also stimulate breast cancer cell growth (30). Thus, women at high risk for breast cancer may be advised by their physicians against consuming too much soy (31). Before formal recommendations regarding soy food consumption can be made, however, more information is needed to make an informed judgment about the benefits and risks of soy. Be that as it may, consistent health messages from all sources should help to prevent further misinformation.

This research was supported in part by grants from the Cancer Research and Prevention Foundation and the National Institutes of Health (CA107115, CA81867).

The authors acknowledge the Population Studies Facility for data management support.

\section{References}

1. Healthful attributes spur soy consumption. Prepared Foods. 1997;166:107-109.

2. Parle E. Soy products try to penetrate the mainstream. Chemical Market Reporter. 2000;257:14.

3. Henkel J. The soy health claim. FDA Consumer. 2000;May-June:17.

4. Ohr LM. A magic bean sprouts. Prep Foods. 2000;169: 60-62.

5. Kendler PB. Nonmeat of the matter: Hunters for vegetable-based items are stalking the frozens aisles, and as soy and veggie volume approaches the roar level retailers are staking out territory to bag the results. Supermarket News. 2000;May 1:61.

6. Shu XO, Jin F, Dai Q, Wen W, Potter JD, Kushi LH, Ruan Z, Gao Y, Zheng W. Soyfood intake during adolescence and subsequent risk of breast cancer among Chinese women. Cancer Epidemiol Biomarkers Prev. 2001;10:483-488.

7. Wu A, Ziegler R, Nomura A, West DW, Kolonel LN, Horn-Ross PL, Hoover RN, Pike MC. Soy intake and risk of breast cancer in Asians and Asian Americans. Am J Clin Nutr. 1998;68(6 Suppl):S1437-S1443.

8. Wu AH, Wan P, Hankin J, Tseng C-C, Yu MC, Pike MC. Adolescent and adult soy intake and risk of 
breast cancer in Asian-Americans. Carcinogenesis. 2002;23:1491-1496.

9. Harris PF, Remington PL, Trentham-Dietz A, Allen CI, Newcomb PA. Prevalence and treatment of menopausal symptoms among breast cancer survivors. $J$ Pain Symptom Manage. 2002;23:501-509.

10. Maskarinec G, Meng L. An investigation of soy intake and mammographic characteristics in Hawaii. Breast Cancer Res Treat. 2001;3:134-141.

11. Hargreaves DF, Potten CS, Harding C, Shaw LE, Morton MS, Roberts SA, Howell A, Bundred NJ. Twoweek dietary soy supplementation has an estrogenic effect on normal premenopausal breast. J Clin Endocrinol Metab. 1999;84:4017-4024.

12. Petrakis NL, Barnes S, King EB, Lowenstein J, Wiencke J, Lee MM, Miike R, Kirk M, Coward L. Stimulatory influence of soy protein isolate on breast secretion in pre- and postmenopausal women. Cancer Epidemiol Biomarkers Prev. 1996;5:785-794.

13. US Department of Agriculture, Iowa State University. Available at: http://www.nal.usda.gov/fnic/foodcomp/ Data/isoflav/isoflav.html. Accessed October 20, 1999.

14. Pillow P, Duphorne C, Chang S, Contois JH, Strom SS, Spitz MR, Hursting SD. Development of a database for assessing dietary phytoestrogen intake. Nutr Cancer. 1999;33:3-19.

15. Kirk P, Patterson RE, Lampe J. Development of a soy food frequency questionnaire to estimate isoflavone consumption in US adults. J Am Diet Assoc. 1999;99: 558-563.

16. Franke AA, Hankin JH, Yu MC, Maskarinec G, Low $\mathrm{SH}$, Custer LJ. Isoflavone levels in soy foods consumed by multiethnic populations in Singapore and Hawaii. J Agric Food Chem. 1999;47:977-986.

17. Liggins J, Bluck LJC, Runswick S, Atkinson C, Coward WA, Bingham SA. Daidzein and genistein content of fruits and nuts. J Nutr Biochem. 2000;11:326331.

18. Horn-Ross PL, Barnes S, Lee M, Coward L, Mandel JE, Koo J, John EM, Smith M. Assessing phytoestrogen exposure in epidemiologic studies: development of a database (United States). Cancer Causes Control. 2000;11:289-298.

19. American Society of Clinical Oncology Policy Statement Update: Genetic Testing for Cancer Susceptibility. J Clin Oncol. 2003;21:2397-2406.
20. Willet WC, Sampson L, Browne ML, Stampfer MJ, Rosner B, Hennekens CH, Speizer FE. The use of a self-administered questionnaire to assess diet four years in the past. Am J Epidemiol. 1988;127:188-199.

21. Atkinson C, Skor HE, Fitzgibbons ED, Scholes D, Chen C, Wahala K, Schwartz SM, Lampe JW. Overnight urinary isoflavone excretion in a population of women living in the United States, and its relationship to isoflavone intake. Cancer Epidemiol Biomarkers Prev. 2002;11:253-260.

22. Frankenfeld C, Patterson R, Kalhorn T, Skor H, Howald W, Lampe J. Validation of a soy food frequency questionnaire with plasma concentrations of isoflavones in US adults. $J$ Am Diet Assoc. 2002;102: 1407-1413.

23. Bus A, Worsley A. Consumers' sensory and nutritional perceptions of three types of milk. Public Health Nutr. 2003;6:201-208.

24. Glanz K, Basil M, Maibach E. Why Americans eat what they do: Taste, nutrition, cost, convenience and weight control concerns as influences on food consumption. J Am Diet Assoc. 1998;10:1118-1126.

25. James C, James N, Davies D, Harvey P, Tweddle S. Preferences for different sources of information about cancer. Patient Educ Couns. 1999;37:273-282.

26. Biley A, Robbe I, Laugharne C. Sources of health information for people with cancer. Br J Nurs. 2001; 10:102-106.

27. Carlsson M. Cancer patients seeking information from sources outside the health care system. Support Care Cancer. 2000;8:453-457.

28. Ayoob K, Duyff R, Quagliani D. Position of the American Dietetic Association: Food and nutrition misinformation. J Am Diet Assoc. 2002;102:260-266.

29. Patterson RE, Kristal AR, White E. Do beliefs, knowledge, and perceived norms about diet and cancer predict dietary change? Am J Public Health. 1996;86: 1394-1400.

30. Allred CD, Allred KF, Ju YH, Virant SM, Helferich WG. Soy diets containing varying amounts of genistein stimulate growth of estrogen-dependent (MCF-7) tumors in a dose-dependent manner. Cancer Res. 2001;61:5045-5050.

31. Kurzer MS. Phytoestrogen supplement use by women. J Nutr. 2003;133(suppl):S1983-S1986. 